\title{
ANALISIS HASIL REKONDISI MESIN FRAIS ACIERA F3 TERHADAP PENGUJIAN GEOMETRIS, UJI JALAN DAN UJI GETARAN
}

\author{
Fajar Aswin ${ }^{1}$, M. Riva'i², Dedy Firmansyah ${ }^{3}$, Akmarul Umam ${ }^{4}$ \\ 1,2,3,4 Jurusan Teknik Mesin, Politeknik Manufaktur Negeri Bangka Belitung \\ Sungailiat, Bangka Belitung, Indonesia, 33211 \\ Kawasan Industri Air Kantung, Sungailiat-Bangka, 33211 \\ Tel: 0717-93586, Fax: 0717-93585, fajar@polman-babel.ac.id
}

\begin{abstract}
The recondition of the Aciera f3/07 milling machine has been done to restore the machine condition to be ready for use. The machine was damaged and caused the machine to be unable to operate and made electrical and mechanical components fail. The feasibility of the machine is tested to see the achievement of the purpose of machine reconditioning. This paper aims to see the results of the geometric testing of the machine compared with the results of running test and the vibration measurement of the machine parts. This study uses an experimental method, where damage to the machine will be identified and the damage will be immediately carried out repairs or replacement of spare parts. Furthermore, machine performance was testing including machine geometry testing, vibration testing and running test in accordance with ISO-1708 standards. The test results show that there is no significant difference between the results of the geometric precision testing of the machine on vibration testing and road testing. This can indicate that all three tests can be used as a reference in validating the results of machine repair, especially repairing irregularities in the geometric accuracy of the Aciera F3 milling machine.
\end{abstract}

Keywords: Machine reconditioning, milling machines, geometric testing, running test, vibration measurement

\begin{abstract}
Abstrak
Rekondisi mesin frais Aciera f3/07 telah dilakukan untuk mengembalikan kondisi mesin agar siap digunakan. Mesin tersebut mengalami kerusakan sehingga menyebabkan mesin tidak dapat dioperasikan dan menyebabkan komponen elektrik dan mekanik mengalami gagal. Kelayakan mesin diuji untuk melihat ketercapaian dari tujuan rekondisi mesin. Tulisan ini bertujuan untuk melihat hasil pengujian geometris mesin yang dibandingkan dengan hasil pengujian jalan dan pengujian getaran bagian mesin. Penelitian ini menggunakan metode eksperimental, dimana kerusakan mesin yang terjadi akan diidentifikasi kerusakannya dan langsung dilakukan perbaikan atau penggantian suku cadang. kemudian dilakukan pengujian kinerja mesin diantaranya pengujian geometri mesin, pengujian vibrasi dan pengujian jalan sesuai dengan standar ISO-1708. Hasil pengujian menunjukan bahwa tidak ada perbedaan signifikan antara hasil pengujian ketelitian geometris mesin terhadap pengujian getaran dan pengujian jalan. Hal ini dapat menunjukan bahwa ketiga pengujian dapat dijadikan sebagai acuan dalam memvalidasi hasil perbaikan mesin khususnya perbaikan penyimpangan ketelitian geometris mesin frais Aciera F3.
\end{abstract}

Kata kunci : rekondisi mesin, mesin frais, pengujian geometris, uji jalan, getaran

\section{PENDAHULUAN}

Saat ini proses produksi selalu dituntut untuk menghasilkan produk berkualitas tinggi, hal ini tidak dapat dipisahkan dari beberapa faktor seperti, kondisi mesin yang digunakan untuk proses produksi. Mesin frais adalah mesin pemotong logam dengan gerakan utama spindel berputar yang banyak digunakan untuk proses produksi, mesin ini mampu melakukan banyak variasi bentuk kerja dibandingkan mesin lainnya, seperti permukaan lurus atau lekukan, celah, roda gigi, lubang, ekor burung, dan lainnya menggunakan berbagai bentuk alat pemotong. Karena mesin ini digunakan untuk membuat produk, maka keakuratan produk yang dibuat sangat tergantung pada kondisi ketelitian geometris mesin tersebut. Beberapa faktor yang mempengaruhi ketelitian geometris mesin meliputi: akurasi permukaan referensi, akurasi gerak linier, akurasi gerak spindel dan akurasi perpindahan bagian - bagian mesin. Mesin frais yang telah digunakan untuk jangka waktu tertentu akan mengalami keausan pada berbagai komponen yang menyebabkan penyimpangan dari kondisi awal. Jumlah penyimpangan yang terjadi dapat dilihat dari 
hasil uji ketelitian geometri. Untuk peralatan mesin yang telah mengalami rekondisi, data uji geometrik juga bisa digunakan sebagai ukuran keberhasilan upaya rekondisi. Untuk mengetahui ketelitian geometrik suatu mesin, perlu dilakukan pengujian dengan mengacu pada standar. Pengembangan prosedur pengujian ini dipelopori oleh $\mathrm{G}$. Schlesinger dengan membuat standar kelayakan untuk peralatan $\operatorname{mesin}[1]$.

Mesin frais Aciera $\mathrm{f} 3$ adalah salah satu jenis mesin frais yang digunakan di Laboratorium Mekanik Polman Negeri Bangka Belitung untuk mendukung proses belajar mengajar untuk mata kuliah praktik proses permesinan mengefrais. Dari beberapa mesin frais Aciera f3 yang ada, mesin frais no 07 mengalami kerusakan yang serius sehingga kondisi mesin tersebut tidak dapat dipakai untuk praktik mahasiswa. Berdasarkan hal tersebut diatas, telah dilakukan tindakan perbaikan untuk mengembalikan kondisi (rekondisi) mesin frais Aciera $\mathrm{f} 3 / 07$ yang difokuskan pada masalah : perbaikan sistem kelistrikan, perbaikan penyimpangan geometris dan pengujian kinerja mesin (putaran spindle, uji jalan, serta getaran). Adapun metode pelaksanaan yang diterapkan adalah metode observasi dengan melihat hubungan sebab akibat menggunakan analisa 5 (lima) mengapa untuk menyelesaikan permasalahan yang ditimbul dari hasil pengumpulan data awal yang kemudian dilanjutkan dengan proses perencanaan perbaikan dan tindakan perbaikan. Artikel ini akan membahas analisa hasil perbaikan mesin frais Aciera F3 terhadap pengujian ketelitian geometris dan pengujian kinerja (putaran spindle, uji jalan pada benda kerja, serta pengujian getaran).

\section{METODE PENELITIAN}

Metode penelitian yang diterapkan pada artikel ini menggunakan metode penelitian eksperimental, dimana kerusakan mesin dianalisa berdasarkan penyimpangan geometris mesin terhadap parameter ukuran, posisi dan bentuk masing - masing komponen mesin terhadap komponen mesin lainnya baik secara statis maupun dinamis. Kemudian tindakan perbaikan dilakukan untuk mengembalikan kondisi geometris mesin sesuai standar toleransi yang diizinkan untuk masing - masing parameter berdasarkan standar ISO-1708 untuk mesin perkakas dengan kategori power medium. Gambar 2.1 menunjukan alur penelitian yang dilakukan untuk menguji hasil pengujian geometris yang kemudian dibandingkan dengan pengujian kinerja mesin berdasarkan standar getaran dan hasil uji jalan terhadap benda kerja.

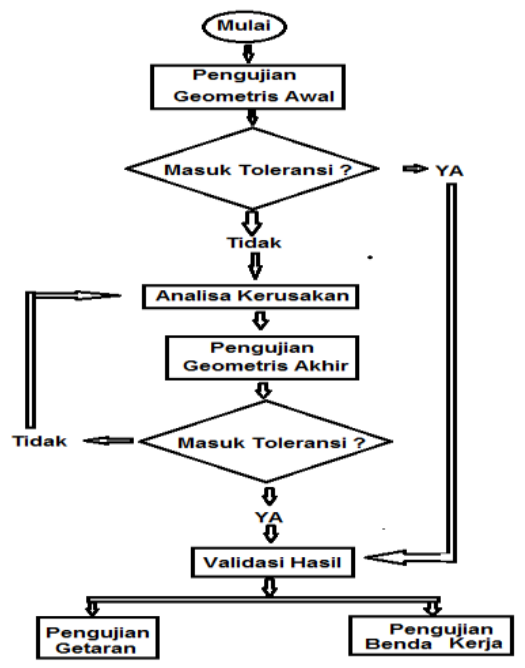

Gambar 1. Alur Penelitian

3. HASIL DAN PEMBAHASAN

3.1 Pengujian Awal ketelitian geometris mesin

Sebelum ketelitian geometris mesin diperbaiki, kondisi awal geometris mesin (initial condition) terlebih dahulu harus dilakukan pengukuran untuk kemudian dibandingkan dengan standar toleransi yang diizinkan sesuai dengan spesifikasi mesin (ISO-1708) [2]. Berdasarkan hasil pengukuran awal, kemudian dilakukan tindakan - tindakan perbaikan termasuk penyetelan sesuai kaidah teknik (Kalibrasi mesin perkakas) untuk parameter - parameter yang terdapat penyimpangan ketelitian. Analisa kerusakan 
dilakukan dengan metode 5-Why [3] untuk menentukan tindakan perbaikan yang paling efektif. Tabel 1 dan Tabel 2 menunjukan hasil pengukuran awal dan tindakan perbaikan yang dilakukan.

Tabel 1. Hasil Pengukuran Awal

\begin{tabular}{|c|c|c|c|c|c|c|c|c|c|c|c|}
\hline \multirow[b]{2}{*}{ No } & \multirow[b]{2}{*}{ Area } & \multirow[b]{2}{*}{ Deskripsi Pengukuran } & \multirow[b]{2}{*}{ Toleransi } & \multirow{2}{*}{\begin{tabular}{|c|} 
Hasil \\
Pengukuran \\
Awal (mm) \\
\end{tabular}} & \multirow[b]{2}{*}{ Keterangan } & \multirow[b]{2}{*}{ No } & \multirow[b]{2}{*}{ Area } & \multirow[b]{2}{*}{ Deskripsi Pengukuran } & \multirow[b]{2}{*}{ Toleransi } & \multirow{2}{*}{$\begin{array}{c}\text { Hasil } \\
\text { Pengukuran } \\
\text { Awal (mm) }\end{array}$} & \multirow[b]{2}{*}{ Keterangan } \\
\hline & & & & & & & & & & & \\
\hline 1 & \multirow{7}{*}{ 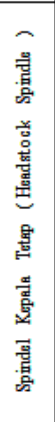 } & $\begin{array}{l}\text { Eksentrisitas lancip } \\
\text { internal }\end{array}$ & 0,005 & 0,00 & Masuk toleransi & 11 & 螰 & $\begin{array}{l}\text { Terhadap belakang } \\
\text { cylinder }\end{array}$ & 0,02 & 0,02 & Masuk toleransi \\
\hline 2 & & Perubahan Aksial & 0,005 & 0.00 & Masuk toleransi & 12 & 营 & Terhadap depan cylinder & 0,02 & 0,25 & $\begin{array}{c}\text { Tidakmasuk } \\
\text { toleransi }\end{array}$ \\
\hline 3 & & $\begin{array}{l}\text { Eksentrisitas pada } \\
\text { adaptor }\end{array}$ & 0,005 & 0,05 & $\begin{array}{c}\text { Tidakmasuk } \\
\text { toleransi }\end{array}$ & 13 & \multirow{3}{*}{$\begin{array}{l}\text { 兽 } \\
\text { 旁 }\end{array}$} & Kemiringan Vertical & 0,015 & 0,02 & $\begin{array}{c}\text { Tidakmasuk } \\
\text { toleransi }\end{array}$ \\
\hline 4 & & \begin{tabular}{|l|} 
Perubahan Sumbu \\
Horizontal
\end{tabular} & 0,015 & 0,01 & Masuk toleransi & 14 & & Kemiringan horis ontal & 0,02 & 0,08 & $\begin{array}{c}\text { Tidakmasuk } \\
\text { toleransi }\end{array}$ \\
\hline 5 & & \begin{tabular}{|l|} 
Perubahan Sumbu \\
Vertical
\end{tabular} & 0,015 & 0,01 & Masuk toleransi & 15 & & Kemiringan Tee-Slots & 0,02 & 0,08 & $\begin{array}{c}\text { Tidak masuk } \\
\text { toleransi }\end{array}$ \\
\hline 6 & & Keratagn Slot dalam & 0,01 & 0,00 & Masuk toleransi & 16 & \multirow{5}{*}{ 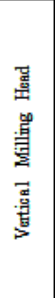 } & $\begin{array}{l}\text { Eksentrisitas lancip } \\
\text { internal }\end{array}$ & 0,005 & 0,00 & Masuk toleransi \\
\hline 7 & & Kerataan slot luar & 0,01 & 0,00 & Masuk toleransi & 17 & & Perubahan Aksial & 0,005 & 0,07 & $\begin{array}{l}\text { Tidak masuk } \\
\text { toleransi }\end{array}$ \\
\hline 8 & \multirow{3}{*}{ 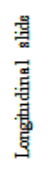 } & Longitudinal Slide Table & 0,02 & 0,09 & $\begin{array}{c}\text { Tidakmasuk } \\
\text { toleransi }\end{array}$ & 18 & & Eksentrisitas pada arbor & 0,02 & 0,04 & $\begin{array}{c}\text { Tidakmasuk } \\
\text { toleransi }\end{array}$ \\
\hline 9 & & $\begin{array}{l}\text { Pengukuran slide } \\
\text { horizontal }\end{array}$ & 0,02 & 0,00 & Masuk toleransi & 19 & & Putaran 0=-180. & 0,02 & 0,87 & $\begin{array}{c}\text { Tidak masuk } \\
\text { toleransi }\end{array}$ \\
\hline 10 & & \begin{tabular}{|l|} 
Pengukuran slide \\
vertical
\end{tabular} & 0,01 & 0,00 & Masuk toleransi & 20 & & Putaran 90:-270= & 0,02 & 0,9 & $\begin{array}{c}\text { Tidakmasuk } \\
\text { toleransi }\end{array}$ \\
\hline
\end{tabular}

Tabel 2. Tindakan Perbaikan terhadap penyimpangan

\begin{tabular}{|c|c|c|c|c|}
\hline No & $\begin{array}{c}\text { Item } \\
\text { pengukura }\end{array}$ & Tolersansi & $\begin{array}{c}\text { Pengukuran } \\
\text { awal }\end{array}$ & $\begin{array}{c}\text { langkah } \\
\text { perbaikan }\end{array}$ \\
\hline 1 & $\begin{array}{l}\text { Eksentrisit } \\
\text { as pada } \\
\text { adsptor }\end{array}$ & 0,005 & 0,05 & $\begin{array}{l}\text { Gib di pasang } \\
\text { rata dengan } \\
\text { permukasn } \\
\text { bagian slideway } \\
\text { sumbu y, } \\
\text { kemudian } \\
\text { dikencangkan } \\
\text { dengan adjust } \\
\text { worm }\end{array}$ \\
\hline 2 & $\begin{array}{l}\text { Longitudin } \\
\text { al Slide } \\
\text { Table }\end{array}$ & 0,02 & 0,09 & $\begin{array}{l}\text { Gib di pasang } \\
\text { rata dengan } \\
\text { permukaan } \\
\text { bagian slideway } \\
\text { sumbu } \mathrm{x} \text {, } \\
\text { kemudian } \\
\text { dikencangkan } \\
\text { dengan adjust } \\
\text { worm }\end{array}$ \\
\hline 3 & $\begin{array}{l}\text { Terhadap } \\
\text { depan } \\
\text { cylinder }\end{array}$ & 0,02 & 0,25 & $\begin{array}{l}\text { Baut penahan } \\
\text { pada bagian liri } \\
\text { dan kanan } \\
\text { table di setel }\end{array}$ \\
\hline 4 & $\begin{array}{l}\text { Kemiringa } \\
\text { n Vertical }\end{array}$ & 0,015 & 0,02 & $\begin{array}{l}\text { Baut penahan } \\
\text { pada bagian } \\
\text { atas dan bawah } \\
\text { table di setel }\end{array}$ \\
\hline
\end{tabular}

\begin{tabular}{|c|c|c|c|c|}
\hline No & $\begin{array}{c}\text { Item } \\
\text { pengukura }\end{array}$ & Toleransi & $\begin{array}{c}\text { Pengukuran } \\
\text { awsal }\end{array}$ & $\begin{array}{c}\text { langkah } \\
\text { perbaikan }\end{array}$ \\
\hline 5 & $\begin{array}{c}\text { Kemiringa } \\
n \\
\text { horis ontal }\end{array}$ & 0,02 & 0,08 & $\begin{array}{c}\text { Baut penahan } \\
\text { pada bagian } \\
\text { bawah table di } \\
\text { setel }\end{array}$ \\
\hline 6 & $\begin{array}{l}\text { Kemiringa } \\
\text { n Tee-Slots }\end{array}$ & 0,02 & 0,08 & $\begin{array}{l}\text { Baut penahan } \\
\text { pada bagian bir } \\
\text { dan kanan } \\
\text { table di setel }\end{array}$ \\
\hline 7 & $\begin{array}{c}\text { Perubahan } \\
\text { Aksial }\end{array}$ & 0,005 & 0,07 & $\begin{array}{l}\text { Setting busur } \\
\text { penunjuk } \\
\text { kepala adaptar } \\
\text { pada kondisi } \\
\text { "0" , atau } \\
\text { sesuaikan }\end{array}$ \\
\hline 8 & $\begin{array}{c}\text { Elcsentrisit } \\
\text { as pada } \\
\text { arbor }\end{array}$ & 0,02 & 0,04 & $\begin{array}{l}\text { Setting busur } \\
\text { penunjuk } \\
\text { kepala adaptar } \\
\text { pada kondisi } \\
\text { "0", atau } \\
\text { sesuaikan } \\
\text { dengan alat } \\
\text { ukur dial } \\
\text { indicator }\end{array}$ \\
\hline 9 & $\begin{array}{c}\text { Putaran } 0 .- \\
180 .\end{array}$ & 0,02 & 0,87 & \multirow{2}{*}{$\begin{array}{c}\text { Setel } 3 \text { baut } \\
\text { penyangga mgja } \\
\text { di bagian } \\
\text { bawah,sesuaika } \\
\text { n dengan alat } \\
\text { ukur dial } \\
\text { indicator }\end{array}$} \\
\hline 10 & $\begin{array}{l}\text { Putaran } \\
90=-270=\end{array}$ & 0,02 & 0,9 & \\
\hline
\end{tabular}

Berdasarkan hasil pengukuran pada Tabel 1, dari 20 buah parameter pengujian terdapat 10 parameter yang terjadi penyimpangan dan harus diperbaiki. Dari 10 parameter yang mengalami 
penyimpangan kemudian dilakukan analisa kerusakan dengan metode 5 Why untuk menentukan penyebab kerusakan dan perbaikan yang seharusnya dilakukan. Hasil analisa kerusakan dan tindakan perbaikan dirangkum pada Tabel 2.

\subsection{Rancangan Sistem Validasi Hasil Pengujian}

Untuk memvalidasi hasil akhir pengujian ketelitian geometris setelah perbaikan dilakukan pengujian kinerja mesin berdasarkan kondisi getaran spindle utama mesin dan pengujian hasil proses permesinan terhadap benda kerja.

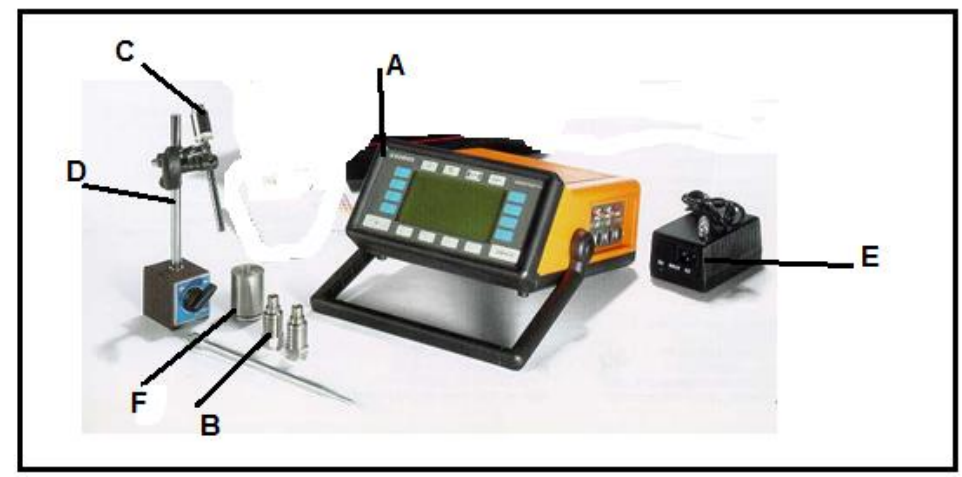

Gambar 2. Alat Pengukur Getaran (VibroPort-41 Schenk)

Pada gambar 3.3 terlihat alat bantu pengujian kinerja berdasarkan getaran menggunakan unit pengukur getaran merek Schenk tipe VibroPort-41 [4] dengan spesifikasi sebagai berikut :

A. Processing Unit dan Display, sebagai pemroses signal analog dan sumber power bagi tranduser B dan C yang kemudian menampilkan hasil pengukuran dalam satuan akselerasi $\mathrm{m} / \mathrm{s} 2$ RMS (Root Mean Square).

B. Sensor getaran tipe akselerometer PiezoElectric Resistive Capitance (PZT, AS-63)[5], dengan nilai sensitivitas $100 \mathrm{mv} / \mathrm{G}$ yang mampu mengukur getaran dengan frekuensi Bandwidth 1$60.000 \mathrm{Khz}$.

C. Sensor tranduser cahaya untuk mengukur kecepatan putaran (RPM) P-84 Optical Reference Sensor [6].

D. Pemegang sensor tranduser cahaya

E. Adaptor power unit processing untuk memberikan tegangan yang dibutuhkan.

F. Magnet holder sebagai mounting device bagi sensor akselerometer agar dapat menempel erat pada bagian mesin yang diukur.

Sensor akselerometer akan ditempatkan pada bagian mesin yang paling dekat dengan komponen mesin yang berputar, dalam penelitian ini diletakkan pada bagian kepala spindle (lebih dekat kepada poros spindle) pada posisi vertical dan horizontal. Pengukuran dilakukan dengan parameter variasi putaran spindle dari 100 - 2000 RPM dengan 4 posisi pengukuran (mendekati kepala spindle dan elemen transmisi utama dari motor utama).

Pengujian kinerja kedua dilakukan dengan cara melakukan proses permesinan untuk memotong benda kerja pada ketiga sumbu bergerak mesin ( $\mathrm{X}, \mathrm{Y}$ dan $\mathrm{Z}$ ) dan membandingkan hasil pemotongan terhadap gambar ukuran yang diinginkan. Hasil pengujian akan ditampilkan pada bagian artikel selanjutnya. 


\subsection{Hasil Pengujian}

\subsubsection{Hasil Pengujian Ketelitian Geometris}

Uji ketelitian geometris bertujuan untuk mendapatkan nilai perubahan komponen - komponen utama mesin berkaitan dengan dimensi, bentuk, dan posisi terhadap komponen - komponen lainnya . Adapun hasil pengujian ketelitian geometris setelah proses perbaikan dapat dilihat pada Tabel 3 berikut.

Tabel 3. Hasil pengujian ketelitian geometris Mesin Aciera F3 setelah diperbaiki

\begin{tabular}{|c|c|c|c|c|c|}
\hline \multirow{3}{*}{ No } & \multirow{3}{*}{ Area } & \multirow{3}{*}{ Deskripsi Pengukuran } & \multirow{3}{*}{ Toleransi } & Hasil & \multirow{3}{*}{ Keterangan } \\
\hline & & & & Pengukuran & \\
\hline & & & & Akhir (mm) & \\
\hline 1 & \multirow{7}{*}{ 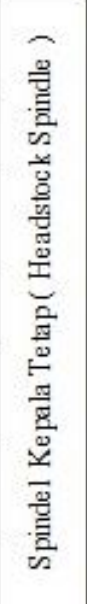 } & $\begin{array}{l}\text { Eksentrisitas lancip } \\
\text { internal }\end{array}$ & 0,005 & 0,004 & Masuk toleransi \\
\hline 2 & & Perubahan Aksial & 0,005 & 0,002 & Masuk toleransi \\
\hline 3 & & $\begin{array}{l}\text { Eksentrisitas pada } \\
\text { adaptor }\end{array}$ & 0,005 & 0,005 & Masuk toleransi \\
\hline 4 & & $\begin{array}{l}\text { Perubahan Sumbu } \\
\text { Horizontal }\end{array}$ & 0,015 & 0,002 & Masuk toleransi \\
\hline 5 & & $\begin{array}{l}\text { Perubahan Sumbu } \\
\text { Vertical }\end{array}$ & 0,015 & 0,000 & Masuk toleransi \\
\hline 6 & & Kerataan Slot dalam & 0,01 & 0,008 & Masuk toleransi \\
\hline 7 & & Kerataan slot luar & 0,01 & 0,006 & Masuk toleransi \\
\hline 8 & $\frac{\pi}{g}$ & Longitudinal Slide Table & 0,02 & 0,014 & Masuk toleransi \\
\hline 9 & 兽 & $\begin{array}{l}\text { Pengukuran slide } \\
\text { horizontal }\end{array}$ & 0,02 & 0,003 & Masuk toleransi \\
\hline 10 & $\stackrel{5}{g}$ & $\begin{array}{l}\text { Pengukuran slide } \\
\text { vertical }\end{array}$ & 0,01 & 0,001 & Masuk toleransi \\
\hline 11 & $\vec{\sigma}$ & $\begin{array}{l}\text { Terhadap belakang } \\
\text { cylinder }\end{array}$ & 0,02 & 0,019 & Masuk toleransi \\
\hline 12 & $>\frac{1}{2}$ & Terhadap depan cylinder & 0,02 & 0,017 & Masuk toleransi \\
\hline 13 & & Kemiringan Vertical & 0,015 & 0,010 & Masuk toleransi \\
\hline 14 & 군 & Kemiringan horisontal & 0,02 & 0,011 & Masuk toleransi \\
\hline 15 & & Kemiringan Tee-Slots & 0,02 & 0,004 & Masuk toleransi \\
\hline 16 & & $\begin{array}{l}\text { Eksentrisitas lancip } \\
\text { internal }\end{array}$ & 0,005 & 0,002 & Masuk toleransi \\
\hline 17 & $\stackrel{\stackrel{M}{I}}{\longrightarrow}$ & Perubahan Aksial & 0,005 & 0,002 & Masuk toleransi \\
\hline 18 & $\sum$ & Eksentrisitas pada arbor & 0,02 & 0,004 & Masuk toleransi \\
\hline 19 & $\stackrel{\vec{D}}{\longrightarrow}$ & Putaran $0=-180=$ & 0,02 & 0,180 & Masuk toleransi \\
\hline 20 & & Putaran 90:-270。 & 0,02 & 0,170 & Masuk toleransi \\
\hline
\end{tabular}


Berdasarkan Tabel 3, dapat dilihat bahwa setiap parameter pengujian telah masuk dalam toleransi yang diizinkan. Pengujian yang dilakukan adalah sebanyak tiga kali untuk memvalidasi hasil pengukuran.

\subsubsection{Data Hasil Pengujian Getaran}

Berikut ini hasil pengukuran getaran menggunakan VibroPort41 merek B\&K dengan spesifikasi tranduser accelerometer AC60 tipe piezocapasitive resistive untuk melihat relevansi hasil pengujian ketelitian geometris mesin terhadap getaran yang ditimbulkan oleh komponen - komponen mesin sesuai dengan standar ISO-10816 tentang pengujian vibration severity untuk mesin yang beroperasi pada kecepatatan putaran 600 sampai 12.000 RPM.

Tabel 4. Hasil Pengujian Getaran Mesin Aciera F3

\begin{tabular}{|c|c|c|c|c|c|c|c|c|c|c|}
\hline \multicolumn{11}{|c|}{ LEMBAR INSPEKSI GETARAN } \\
\hline \multirow[t]{2}{*}{ No. } & \multirow{2}{*}{ gambar } & \multirow{2}{*}{$\begin{array}{l}\text { posisi } \\
\text { sensor }\end{array}$} & \multicolumn{8}{|c|}{ RPM } \\
\hline & & & 100 & 175 & 300 & 400 & 500 & 700 & 1200 & 2000 \\
\hline \multirow[t]{2}{*}{1} & & $\begin{array}{c}\text { Ch1 } \\
\text { vertikal }\end{array}$ & 0,27 & 0,31 & 0,6 & 0,84 & 0,77 & 1,01 & 1,23 & 1,64 \\
\hline & & $\begin{array}{c}\mathrm{Ch} 2 \\
\text { horizontal }\end{array}$ & 0,58 & 0,68 & 0,9 & 1,62 & 1,76 & 1,78 & 2,6 & 2,78 \\
\hline \multirow[t]{2}{*}{2} & & $\begin{array}{c}\text { Ch1 } \\
\text { vertikal }\end{array}$ & 0,08 & 0,1 & 0,17 & 0,58 & 0,29 & 0,66 & 0,87 & 1,03 \\
\hline & & $\begin{array}{c}\mathrm{Ch} 2 \\
\text { horizontal }\end{array}$ & 0,22 & 0,3 & 0,54 & 0,97 & 1,08 & 1,5 & 2,5 & 3,27 \\
\hline \multirow[t]{2}{*}{3} & & $\begin{array}{c}\text { Ch1 } \\
\text { vertikal }\end{array}$ & 0,09 & 0,12 & 0,24 & 0,55 & 0,38 & 0,65 & 0,91 & 1,32 \\
\hline & & $\begin{array}{c}\mathrm{Ch} 2 \\
\text { horizontal }\end{array}$ & 0,26 & 0,33 & 0,6 & 1,16 & 1,11 & 1,61 & 2,22 & 3,14 \\
\hline \multirow[t]{2}{*}{4} & & $\begin{array}{c}\text { Ch1 } \\
\text { horizontal }\end{array}$ & 0,15 & 0,24 & 0,5 & 0,83 & 0,84 & 1,1 & 1,96 & 2,02 \\
\hline & & $\begin{array}{c}\mathrm{Ch} 2 \\
\text { horizontal }\end{array}$ & 0,15 & 0,24 & 0,51 & 0,81 & 0,85 & 1,08 & 1,99 & 2,08 \\
\hline \multirow[t]{2}{*}{5} & & $\begin{array}{c}\text { Ch1 } \\
\text { horizontal }\end{array}$ & 0,24 & 0,34 & 0,59 & 1,15 & 0,88 & 1,52 & 1,87 & 1,75 \\
\hline & & $\begin{array}{c}\mathrm{Ch} 2 \\
\text { horizontal }\end{array}$ & 0,23 & 0,32 & 0,55 & 1,09 & 0,84 & 1,45 & 1,74 & 1,73 \\
\hline
\end{tabular}

Ket :

\begin{tabular}{|l|l|l|l|l|l|}
\hline Good & & Satisfactory & & Unsatisfactory \\
\hline
\end{tabular}

Pengukuran getaran difokuskan pada kepala tetap (Head Stock) dimana spindle utama berada untuk mendapatkan hasil pengukuran yang lebih akurat dan elemen transmisi pemindah putaran. Berdasarkan hasil pengujian getaran yang ditunjukan pada Tabel 4 diatas, diperoleh nilai getaran masih masuk dalam toleransi (satisfactory) untuk kecepatan putaran dibawah 1200 RPM, sedangkan untuk kecepatan putaran diatas 1200 RPM menunjukan nilai diatas toleransi yang diizinkan (unsatisfactory), khususnya untuk pengukuran posisi horizontal. Hal yang memungkinkan untuk mempengaruhi hasil pengukuran adalah besar natural frequency (frekuensi pribadi) spindle berada pada range kecepatan putaran 1200 - 2000 RPM sehingga akan mengakibatkan resonansi yang membuat getaran menjadi dua kali lebih besar. Selain itu, kecenderungan hasil pengukuran pada posisi horizontal lebih besar adalah dikarenakan massa tranduser yang besar terpengaruh oleh gravitasi bumi sehingga menyebabkan hasil pengukuran terdiri dari nilai akselerasi dinamis (dari spindle) dan akselerasi statis (gravitasi bumi).

\subsubsection{Data Hasil Uji Jalan (Benda Kerja)}

Pengujian pada benda kerja dilakukan untuk melihat relevansi kinerja dari mesin terhadap hasil pengujian ketelitian geometris mesin Aciera F3 setelah proses perbaikan. Tabel 5 dibawah menunjukan hasil uji jalan mesin dalam melakukan proses permesinan untuk mengefrais benda kerja dengan spesifikasi material baja ST-37, lebar L sebesar 30,48 mm, lebar D sebesar 10,48 (melintang), putaran spindle 700RPM dan variasi kedalaman pemotongan sebesar 1,14 mm dan 1,50 mm. Gambar 3 menunjukan ukuran benda uji. 


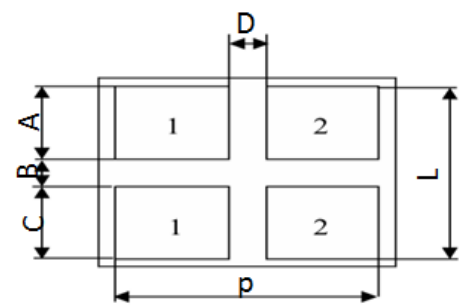

Gambar 3. Ukuran Benda Uji

Tabel 5. Hasil Pengujian Benda Kerja

\begin{tabular}{|c|c|c|c|c|c|c|}
\hline \multirow{2}{*}{ Pengukuran } & \multicolumn{2}{|c|}{$\begin{array}{c}\text { Panjang } \\
\text { Pemakanan }\end{array}$} & \multicolumn{3}{|c|}{$\begin{array}{l}\text { Pergerakan Eretan } \\
\text { meja }(\mathrm{mm})\end{array}$} & \multirow{2}{*}{$\begin{array}{c}\text { Selisi pergerakan eretan } \\
\text { dengan pengukuran } \\
\text { benda kerja }\end{array}$} \\
\hline & $\begin{array}{c}\text { Titik } \\
1\end{array}$ & $\begin{array}{c}\text { Titik } \\
2\end{array}$ & $x$ & y & 2 & \\
\hline A & 10,00 & 10,00 & & 10 & & - \\
\hline B & 10,48 & 10,48 & & 10.48 & & - \\
\hline $\mathrm{C}$ & 10,00 & 10,00 & & 10 & & - \\
\hline $\mathrm{D}$ & 10,48 & 10,48 & 10.48 & & & - \\
\hline \multirow[t]{2}{*}{ Pengukuran } & \multicolumn{2}{|c|}{ Kedalaman } & \multicolumn{3}{|c|}{$\begin{array}{l}\text { Pergerakan Eretan } \\
\text { meja }(\mathrm{mm})\end{array}$} & $\begin{array}{l}\text { Selisi pergerakan eretan } \\
\text { dengan pengukuran }\end{array}$ \\
\hline & 1 & 2 & $\mathrm{x}$ & $y$ & 2 & benda kerja \\
\hline $\mathrm{A}$ & 1,14 & 1,14 & & & 1,14 & - \\
\hline $\mathrm{B}$ & & & & & & - \\
\hline $\mathrm{C}$ & 1,50 & 1,50 & & & 1,50 & - \\
\hline $\mathrm{D}$ & & & & & & - \\
\hline
\end{tabular}

Dari hasil percobaan diatas dapat diketahui pergerakan eretan meja terhadap spindle utama (alat potong) pada sumbu $X$ dan sumbu $Y$ menunjukan tidak ada penyimpangan pergerakan sepanjang $10 \mathrm{~mm}$ dan sesuai dengan skala eretan sebesar $0,02 \mathrm{~mm}(10,48 \mathrm{~mm})$. Begitu juga dengan pergerakan sumbu $Z$ kepala tetap terhadap kedudukan meja eretan tidak menunjukan penyimpangan sepanjang pemakanan kedalaman sebesar $1,50 \mathrm{~mm}$ dan sesuai dengan skala eretan sebesar $0,02 \mathrm{~mm}(1,14 \mathrm{~mm})$.

\section{SIMPULAN}

Berdasarkan hasil pengujian dan analisa dapat ditarik kesimpulan sebagai berikut :

1. Hasil pengujian getaran secara umum masih relevan terhadap Hasil pengujian ketelitian geometris. Tambahan, perlu dipertimbangkan nilai frekuensi pribadi spindle dan massa tranduser akselerometer untuk mengurangi pengaruh gravitasi pada posisi horizontal.

2. Hasil pengujian pada benda kerja menunjukan hasil perbaikan mesin Frais Aciera F3 sesuai dengan hasil akhir pengujian ketelitian geometrisnya.

3. Pengujian getaran dan pengujian jalan (Benda Kerja) dapat dijadikan acuan untuk menilai kelayakan ketelitian geometris mesin.

\section{DAFTAR PUSTAKA}

[1] G. Schlesinger, "Machine Tool Tests and Alignments," Proc. Inst. Mech. Eng., vol. 138, no. 01, pp. 59-119, 1938.

[2] International Organization for Standardization, "Acceptance conditions for general purpose parallel lathes -- Testing of the accuracy." International Organization for Standardization, pp. 1-13, 1983.

[3] O. Serrat, "The Five Whys Technique," in Knowledge Solutions, Springer, Singapore, 2017, pp. 307310.

[4] B\&K, "VIBROPORT 41 Documentation Tehnique," Brüel \& Kjær Vibro GmbH, D-64293 Darmstadt, 2002. .

[5] V. Brüel \& Kjaer, “AS - 063,” Brüel \& Kjær Vibro GmbH, 2017. [Online]. Available: https://www.bkvibro.com/fileadmin/mediapool/Internet/Instructions/Sensors/Acceleration_senso rs/AS-xxx/Instruction_AS063de-en-fr.pdf.

[6] B\&K, “P-84 Optical Reference Sensor Documentation,” Brüel \& Kjær Vibro GmbH, 2011. 